\title{
The corporate takeover of the online public sphere: A critical examination, with reference to 'the New Zealand case'
}

\section{ABSTRACT}

Much communications research is in agreement about the failure of the mass media to adequately facilitate a public sphere of open and reflexive debate necessary for strong democratic culture. In contrast, the internet's decentralised, two-way communication is seen by many commentators to be extending such debate. However, there is some ambivalence among critical theorists as to the future role of the internet in advancing the public sphere. On the one hand, the internet is providing the means for the voicing of positions and identities excluded from the mass media. On the other hand, a number of problems are limiting the extensiveness and effectiveness of this voicing. One of the most significant problems is the corporate colonisation of cyberspace, and subsequent marginalisation of rational-critical communication. It is this problem that I focus on in this article, with reference to examples from what I will refer to as the 'New Zealand online public sphere'. I show how online corporate portals and media sites are gaining the most attention oriented to public communication, including news, information, and discussion. These sites generally support conservative discourse and consumer practices. The result is a marginalisation online of the very voices marginalised offline, and also of the critical-reflexive form of communication that makes for a strong public sphere. I conclude by noting that corporate colonisation is as yet only partial, and control of attention and meaning is highly contested by multiple 'alternative' discursive spaces online.

\section{LINCOLN DAHLBERG}

Co-editor of New Zealand Sociology 


\section{Introduction}

ANY POLITICAL theorists today agree that a strong democracy M requires a vibrant public sphere of open and reflexive debate over problems of living together with difference (see Bauman, 2002; Benhabib, 1996; Boggs, 2000; Bohman, 1996; Dryzek, 2000; Habermas, 1996; Young, 2000). In contemporary, large scale, dispersed and complex societies, mass communications media are required to support such a sphere. However, the mass media have been shown by a variety of critical theorists to have failed in this role (see Boggs, 2000; Curran, 2000; Gandy, 2002; Habermas, 1989; Kellner, 2004; McChesney, 1999; Savigny, 2002). These critics show how the mass media have been captured by conservative interests through state and corporate power. State control is still the paramount influence over mass media discourse in some nations (e.g. China, Burma, Malaysia). However, in liberal-capitalist states, neo-liberal driven deregulation, privatisation, and commercialisation have led to capitalist interests dominating the symbolic production of the mass media. Alternative positions and forms of participation to those promoted in consumer capitalist discourse are marginalised, limiting the open and reflexive contestation of issues necessary for the formation of a strong democratic culture.

This is true in the case of New Zealand, which I focus upon in this article. Throughout New Zealand's history, the mass media have been predominantly owned and controlled by either state or corporate interests. Over the last two decades most newspapers have come under the ownership and control of two publishing groups: Wilson and Horton, which is owned by the Australian media company APN, a subsidiary of Independent News and Media (controlled by the Irish media magnate Tony O'Reilly); and Independent Newspapers Ltd (INL), controlled by News Ltd, the Australian branch of Rupert Murdoch's US-based News Corporation. (However, in July 2003 Fairfax New Zealand Ltd bought out INL, New Zealand's largest media company.) Broadcasting was taken over as a state monopoly in the 1930s. However, since the neoliberal driven restructuring of the New Zealand public sector after 1995, deregulation, privatisation and commercialisation of the mass media have led to the corporate take-over of much of the terrestrial broadcasting system, as well as cable and satellite networks. In addition, commercial imperatives are being applied to the remaining state television channels. ${ }^{1}$ As a result, the discourse of the mainstream New Zealand media is framed by liberal capital- 
ist assumptions. Subjects are positioned as consumers, property owners, and taxpayers, whose needs can be met by individual consumption of products. Accordingly, public issues are structured around what are seen as consumer problems and needs. For instance, a recent debate about Maori customary rights with respect to tribal lands was framed as a debate about private property ownership and the costs to 'the taxpayer' (Kelsey, 2004).

In contrast, a number of critical theorists see the internet as holding the potential to reinvigorate democratic culture. The internet's decentralised, twoway communication is seen as providing space for citizen interaction and debate and thus an alternative to the corporate mass media for expanding and enhancing the public sphere (see Blumler and Gurevitch, 2001; Dahlgren, 2001; Gimmler, 2001; Kellner, 2004; Papacharissi, 2002; 2004). At the same time a number of critical media researchers warn that the internet may be going down a similar path to the mass media, that is, undergoing a corporate colonisation (see Barney, 2000, 2003; Dahlberg, 2002; Fortier, 2001; McChesney, 1999, 2002; Napoli, 1998; Schiller, 1999).

In this article I outline the online practices that may be identified as helping to extend the public sphere and explore the limitations being posed on this extension by corporate interests, with particular reference to examples from what I will refer to as the 'New Zealand online public sphere' (defined below). New Zealand has an active, legally protected civil society and a comparatively high internet access rate, ${ }^{2}$ which together have translated into extensive online civic participation. There are an estimated 16,000 non-commercial organisations and groups with websites in the .nz internet domain (see Ministry of Economic Development, 2003). At the same time, New Zealand has led the way globally in neo-liberal restructuring of the media and telecommunications industries, and successive governments have kept out of the way of the corporate domination of the New Zealand internet domain that has resulted from the internet's commercialisation in the mid-1990s. By April 2003, more than 84 percent of the World Wide Web sites on the .nz domain were owned by commercial organisations, even with many business enterprises locating their websites on the United States' .com domain (ibid). Given this situation, New Zealand offers a good case study of online civic practice in the face of corporate colonisation. Moreover, by focusing on New Zealand, analysis can contribute to a decentring of internet-public sphere research, which up until now has largely explored North American and Western European cases and contexts.

92 PACIFIC JOURNALISM REVIEW 11 (1) 2005 
However, I will not be undertaking an in-depth case study here. Instead, I will draw upon New Zealand examples and combine these with overseas research to develop a general and critical exploration of the corporate threat to the internet expanding the public sphere, where the term 'critical' refers to reasoned problematisation and critique, and is consistent with a general understanding of critical theory as a normative, evaluative approach (here evaluation takes place via the public sphere norm). I start by discussing reasons why the internet may be extending the public sphere. I then explore evidence for a corporate colonisation of cyberspace, focusing particularly upon sites performing as public spaces. I discuss what this colonisation may mean for online democratic culture, and conclude by considering further questions that need to be investigated to better understand the possibilities and threats to internet communication extending the public sphere in the context of corporate domination.

\section{Internet as public sphere, focusing on the New Zealand context}

A cursory examination of internet communication finds that it does indeed provide an alternative to corporate and state controlled mass media. The twoway, decentralised medium offers greater opportunity (for those with access) than state and/or corporate controlled mass media for voicing views, performing identities, encountering diverse ideas and information, and engaging in dialogue and debate with difference. Through email, discussion sites, online publishing and web streaming, a multitude of actors circulate, discuss, and contest a myriad of issues, identities and discourses, related to local, national, and international contexts.

The diversity of 'types' of public discourse online can be illustrated with reference to examples from what can be considered as the ' $\mathrm{NZ}$ online public sphere'. Of course, online communicative arenas and participants are located within a global network of online and offline communication. As such, internet discourse cannot be wholly identified with the concerns of a particular nation-state. For example, the 'independent' (although commercial) online news publication Scoop.co.nz is located on the New Zealand domain and primarily aimed at a New Zealand audience, yet it is read extensively in the United States as an alternative news media source and has even won the US based 'democratic media award' for its independent news coverage (see www.goodwriters.net/dmr2.html). On the other hand, many New Zealand 
based users operating from .nz internet addresses spend their time reading and interacting on sites located on other domains. Still, we can loosely identify a set of sites and communications that roughly constitute discourse that is concerned with, or particularly focused upon, New Zealand issues and identities. This set is made up of the sites and email addresses within the .nz internet domain together with sites located on other domains that are distinctly focused on New Zealand issues and identities.

Given this, what specific sites in the New Zealand domain or related to New Zealand issues can be considered as spaces of public interaction? We can begin by discarding instrumentally focused sites of government administration and business transaction, the latter consisting of a large proportion of online communication. We can also eliminate official decision-making internet spaces, including those of citizen-government interaction. These spaces constitute part of what may be called the formal or official, rather than citizenbased, public sphere (Habermas, 1996). We can also exclude all 'private' sites, those that do not enable the articulation and contestation of generalisable positions (e.g. private family websites that take-for-granted, rather than question, social norms). What do we have left with regards to public sphere-oriented communication on the New Zealand domain or on any site focused on New Zealand issues?

As well as politically oriented e-mail and other inter-personal online communication between individuals, a variety of types of public sphere-oriented discourse online can be identified, including:

- Informal internet discussion spaces, facilitated through e-mail lists, web boards, and Usenet groups.

- Political party sites (for examples see Piper portal at piperpat.co.nz/ $\mathrm{nz} /)^{3}$

- Mass media sites (see Piper portal) and Web portals like Xtramsn.co.nz and Google.co.nz, which will be discussed at length in the next section.

- 'Independent' media such as the Scoop.co.nz and the Aotearoa Independent Media Centre (indymedia.org.nz).

- Weblogs aimed at public discourse. By linking to each other and to the mass media Weblogs create spaces of argumentation between opposing perspectives. Examples of some New Zealand issues-oriented weblogs can be found at blogwise.com/bycountry.

- Online practices of non-government organizations, social movements, 
and single interest groups (see the Piper portal, and for more 'progressive' groups see converge.co.nz).

- Community and cultural groups, including those sites of artistic expression, neighbourhood interaction, and diasporic and indigenous gathering (for examples see Piper portal and New Zealand discussion groups on Yahoo.com). For example, Aotearoa Café offers a vibrant space of democratic debate structured from Maori perspectives that are largely silenced in the mainstream media (http://www.aocafe.com/forums/index.php).

All this makes for a complex, overlapping space of public interaction and contestation, supporting an expansion of the public sphere. However, those researching the possibility of the internet expanding democratic culture have also pointed out significant factors limiting open and reflexive debate online, including inequalities in access and participation, unreflexive communication, fragmentation of discourse into like-minded deliberative enclaves, and state surveillance and censorship (Dahlberg, 2001; Hoar \& Hope 2002; Gomez, 2004; Murdock and Golding, 2004; Sunstein, 2001; Wilhelm, 2000). Paralleling critiques outlined above of the offline corporate media, some commentators have identified a further problem as possibly the greatest threat to online communication extending the public sphere: the corporate 'colonisation' of cyberspace (see, Barney, 2000, 2003; Dahlberg, 2002; Fortier, 2001; McChesney, 1999, 2002; Napoli, 1998; Schiller, 1999). The argument is that powerful media corporations supported by neo-liberal policies are increasingly gaining control of online communication through ownership and control of key online resources.

The result is the reproduction and dominance online of the discourses and instrumentalist practices of consumer capitalism, and the marginalisation of the open and reflexive debate central to strong democratic culture. It is this colonisation threat that I want to focus upon in this article. I will undertake an exploration of this threat with specific reference to examples from the 'New Zealand online public sphere', and particularly the case of Xtramsn.co.nz, the dominant (most accessed) online portal on the New Zealand domain, drawing from participant observations of the site over 2003-2004 and some initial content analysis of news items on the site in July-August 2004.

\section{The corporate colonisation of the internet}

The most immediate colonisation threat to the internet's democratic potential 
is in terms of the increasing corporate domination of the online 'attention economy'. (For discussion of this 'attention economy' see Davenport \& Beck, 2001; Goldhaber, 1997; Hargittai, 2004). Cyberspace presently operates much like the publishing industry. While any individual or group with the necessary financial and cultural resources is free to publish online, getting heard is another matter given the sheer quantity of websites and other cyber-communication. Those actors with the most resources are able to make their voices heard most loudly online, a largely ignored aspect of 'the digital divide'. ${ }^{4}$ In particular, large media corporations (e.g. Disney, Microsoft Network, TimeWarner, Yahoo!) are deploying their massive resources (including established branding, offline content, marketing budgets, and strategic alliances) to draw significant attention to their online spaces, including attention for what is deemed public communication (news, information, discussion). They are doing so through various forms of online and offline advertising and through the ownership and control of a combination of Internet Service Providers (ISPs), search engines, online spaces, web content, and applications software. Internet specific knowledge and skills, or 'net-savvyness', can gain other actors significant online attention, at least for a short time. For instance, a net-savvy user could code their website to maximise the possibility of being noticed by search engines, or they could hack and rewrite popular corporate sites to publicise their own identity, or they could write a popular weblog. However, media corporations have also acquired an abundance of this communications resource (i.e. net-savvyness). Major corporations simply hire the best internet programmers, hackers, and writers.

Media corporations first work to dominate online attention by operating ISPs and/or search and directory systems, which transform these corporations' homepages into cyber-portals. By acting as an ISP, a corporation can ensure that subscribers' first entry point into cyberspace is via the corporation's homepage. ${ }^{5}$ These ISP homepages include search engines and directory services, which further turn these corporate homepages into portals, providing not only a place to enter cyberspace but a point from where users can (and do) continually return to for the start of all new online 'journeys'. In some cases, companies like Yahoo! and Google have successfully operated as portals without operating ISPs, by becoming known as the best place(s) to go to travel through cyberspace.

By moving people through their cyber-portals, these corporations make money from both subscribers (for those acting as ISPs) and advertisers (sell- 
ing audience). However, to maximise possible revenue from subscribers and advertisers, the homepages of these corporations are designed to do more than port people into cyberspace. The sites are also designed as content and service spaces to attract more users for longer. This not only increases subscriber numbers but (more significantly) entices more advertisers. Users are not so much directed out into cyberspace at large, as a pure portal would do, but pointed towards the portal's own content and services, including news and information, entertainment, shopping, chat channels, discussion forums, etc. The idea is to structure a total online experience around the portal in order to both attract greater user numbers and to keep attention focused on the site for as long as possible, and so 'deliver' more users to advertisers. In the process, these sites could be described as online hubs, combining cyberportals with central online information and meeting places. Moreover, by offering news and interaction services, in addition to the private functions offered, these sites can be seen as performing the role of the public sphere.

Take for example Xtramsn, which has over 50 per cent of the ISP market in New Zealand. ${ }^{6}$ Xtramsn does not simply act as an internet portal. Based on a strategic alliance between the dominant telecommunications corporation in New Zealand (Telecom New Zealand) and Microsoft Network (MSN), Xtramsn has become a content and web service provider. It performs the role of the public sphere by offering news and information and bulletin board discussion groups (MSN's). In addition, it provides a search engine (MSN's), an e-mail service, online shopping malls, various directory services, online games, house and car purchasing databases, a kids corner with games and educational material, travel information and booking shop (Air New Zealand's), music and video streaming and sales, games, a cyber-dating service (match.com's), MSN Hotmail, MSN Messenger, and more. The site keeps its search engine reasonably discrete, foregrounding its own content and service offerings in order to keep users on its site for as long as possible.

The success of these corporate hubs at attracting attention can be seen from internet traffic patterns. Nielson//NetRatings' research shows that in all the countries that it surveys, a handful of hubs generally dominates the rankings of the most popular sites, with Microsoft, Yahoo!, Google, and Time Warner (with its America Online sites) consistently ranking as the top parent companies. ${ }^{7}$ Even in non-English speaking, non-liberal capitalist countries, a select few corporate sites top the user attention rankings. For instance, in China, 
which boasts the second (after the United States) highest number of citizens actively participating online, five corporate hubs have captured a large proportion of user attention, including Google and Yahoo!, which bow to Chinese Government censorship (Liang, 2003; Reporters Without Borders, 2004).

The pattern is the same for the 'New Zealand Online Public Sphere'. The most popular web properties on all domains visited by New Zealanders are corporate hubs (Xtramsn, Microsoft, Google, Yahoo!, Time Warner), with Xtramsn consistently gaining double the audience of any other web property visited (Nielsen//Netratings, 2004). In terms of sites specifically on the New Zealand domain, after Xtramsn, three of the top ten properties (all commercial) are those of commercial offline news media: nzherald.co.nz, stuff.co.nz, and nzoom.co.nz (TVNZ's site) (ibid). ${ }^{8}$ This reflects a global pattern in terms of sites explicitly performing as the public sphere: after corporate hubs, the most popular spaces of public discourse are the online sites of the dominant news media. This is true throughout the Asia-Pacific region, despite cultural and political differences. In Australia, the most popular online news sites, after the hubs, are those owned by major telecommunications and media companies (see www.redsheriff.com/us/news/news_3_89.html). The same is true for Japan (See www.japanmediareview.com). In China a matrix of state and corporate media dominate online attention for news (Liang, 2003). In the United States, research clearly shows that the sites of the corporate media are the favoured source for news (Kohut \& Raine, 2003; Liang, 2003, p. 48; Pew Center, 2004; Raine, Fox, \& Fellows, 2003).

Overall, the online attention for news is dominated by mainstream corporate news media, whether via their own sites or through corporate hubs. In comparison, independent and non-corporate news sites struggle to gain large and mainstream audiences. Alexa.com, which ranks all global websites based on traffic, placed indymedia.org at around 4000 in June 2004 (based on aggregated traffic to all indymedia sites), while the hubs Yahoo!, MSN, Google, and Microsoft took the first four spots, CNN and the BBC placed 13th and 14th respectively, while the New York Times sat at 40th most popular site globally. There are some exceptions to this corporate domination of online news, such as the commercial but 'fiercely independent', press-release-driven, internet news agency Scoop.co.nz, which ranks 12th most popular site in the New Zealand domain (Nielsen//NetRatings, 2004). However, the overall situation is one of attention domination by corporate hubs and media sites. 
Of course, much public sphere-oriented activity is taking place outside these dominant corporate hubs and media sites, as the typology above indicates. Moreover, we cannot say exactly how people are using these dominant sites. However, we can say that these corporate hubs and media sites are gaining the most attention, a situation that parallels that of the offline press where dominant newspapers exist within a context of multiple contesting but marginalized alternative publications. Thus, for understanding the internet's impact on the public sphere it is important to examine how these dominant sites perform publicity. This is the task of the next section.

\section{Discourses and practices promoted by dominant sites of publicity}

To examine the implications that the corporate domination of attention has for the internet extending the public sphere, we need to ask what discourses and practices are facilitated on corporate hubs and news media sites. I will explore this question by first examining the content of news and information offered by these sites, before looking at citizen discussion spaces provided. I will deal with corporate hubs and news media sites separately, because they tend to perform publicity differently. Here I do not intend an in-depth examination. Rather, I provide an exploratory overview of what is on offer, and identify any significant limitations these spaces pose to extending the public sphere. For this overview I draw on available research of corporate news sites, as well as my own initial case study research of the New Zealand corporate internet hub Xtramsn.co.nz.

\section{News and information content of corporate hubs and news sites}

Starting with the corporate hubs, one could possibly think very positively about the content they provide in terms of the public sphere. Because they draw large numbers of readers into their online spaces and provide extensive news reports from various sources, they could be seen as bringing together diverse positions for contestation in central public arenas, overcoming both the fragmentation of the internet into highly focused interest groups and the partiality of the mass media. However, the multiplicity of news and information provided by these spaces does not necessarily translate into diversity. When not simply publishing infotainment, these corporate spaces draw upon dominant news media sources. By attracting attention to these news and information offerings, the corporate hubs narrow the diversity available to 
their users, tying content to conservative news values and dominant ideologies. For example, Xtramsn's news consists of short print, audio, and video clips drawn from Reuters (for international news), the private radio network Newstalk ZB (for local news), and TVNZ (for its broadband service), as well as consumer lifestyle advice stories designed by Xtramsn and its sponsors (primarily for advertising). Even Google.com, despite drawing from over 4500 web-based news sources, shows a bias toward big media in its news selection and algorithm programming (see Dahlberg, 2005).

Corporate news sites, in comparison to the general hubs, tend to strongly signify their news coverage as professional reporting: objective, reliable, and relevant. However, this is no different from how offline news is signified, and does not ensure the representation of any greater range of positions. Despite the internet offering news editors the opportunity to represent diverse views on any story, corporate media have so far tended to develop their online reports from the same pool of stories as their offline offerings and along the same editorial lines, and thus continue to represent most positively and most frequently conservative institutional voices (Boczkowski, 2002, p. 247; Zimmermann \& Koopmans, 2003). Texts are generally written within the terms of dominant discourses in the same way that they have been shown (by critical media researchers) to do in their offline publications and broadcasts.

\section{Discussion groups provided}

What about the many discussion groups provided by the corporate hubs (e.g. Yahoo! groups, MSN groups)? These discussion spaces do often allow for much articulation and contestation of positions. For instance, Xtramsn provides a direct link to MSN's groups, which offer space for anyone connected to the internet to set up any (legal) discussion. There are many thousands of different groups on offer through MSN, including groups situated on a dedicated Xtramsn 'have your say' web site that encourages discussion on issues specifically related to New Zealand news (see http://groups.msn.com/ XtraNewsCommunity/messageboard.msnw). However, the way the discussions are situated and performed on these hubs tends to marginalise critical voices. Critical-reflexive communication is buried among a myriad of specialised interest groups, including many spaces of mutual support and privatised consumption (market transactions, gossip, titillation, etc) (Patelis, 2000). Xtramsn's 'have your say' message boards are difficult to find on the site, 
tucked away within 'New Zealand news' pages, and largely made up of private chat and dogmatic rant (Xtra's commercial and entertainment orientation is not conducive to a deliberative environment).

Corporate news sites provide discussion spaces less often than the hubs. Many site owners do not see public discussion as an important function for online news, despite the possibility offered by the medium and the influence of public journalism values in news work. None of the three most visited New Zealand commercial news media web sites (nzherald.co.nz, stuff.co.nz, nzoom.co.nz) offer discussion boards. The Stuff site does offer a space for (edited) comment on news articles, much like a letters-to-the-editor section of newspapers, but does not provide for public discussion involving reciprocation between participants. Some news sites, particularly those that view themselves as professional and serious international news media (e.g. New York Times.com and Guardian.co.uk), do provide discussion spaces where vibrant and critical engagement on issues can be found (Boczkowski, 2002, 2004; Light \& Rogers, 1999; Schultz, 2000; Tanner, 2001). However, these discussions tend to suffer a number of limitations: they are separated from the fore-grounded editorial material, are fragmented into multiple groups of interest (thus discouraging critical-reflexive debate central to the public sphere), tend to be influenced (in agenda and type of argumentation) by the ideological slant of news items, and are blighted by dominant posters and 'flame fests'.

\section{Structuring of consumer model of politics}

These hubs and corporate media sites not only marginalize critical voices, they generally support the constitution of an instrumental-individualist consumer model of politics, rather than a critical-reflexive communicative model. Participants are encouraged to perform as consumers through individualised, commercialised, and instrumentalised discourses and practices. Participants are positioned as consumers not only by the advertising and shopping pervading these sites, but also by the form of news, information, and interaction provided. This is particularly the case with corporate hubs. On these sites short and often entertainment-oriented news clips are provided that make for easy consumption, rather than for critical reflection. These clips are commonly written as consumer advice, interlaced with various forms of advertising and sponsored stories containing direct links to advertiser sites. Thus 
marketing does not simply confront the user as banner and pop-up advertisements distinct from news, but can be found written as stories and placed within lists of news item hyper-links. Furthermore, those interactive features that are offered tend to be individualized and instrumental, even when somewhat publicly-oriented - when going beyond simply marketing and privatised forms of interaction. As well as news written as individual consumer advice, this individualization and instrumentalisation of interaction includes: hyperlinks directing participants to personal consumer interests, 'daily me' news and information customisation (e.g. My Yahoo!, My MSN), and 'interactive' instruments such as polls and petitions for voicing private views. ${ }^{10}$

Take Xtramsn for example. Xtramsn's homepage provides an initial list of hyperlinked news-story headlines that all appear in the same form (font style and size, register, colour), signifying equal value between stories. ${ }^{11}$ Yet, the stories include everything from 'hard' political news to tabloid style sensationalism, celebrity gossip, and advertorials. Moreover, 'serious' international, local, and business news stories appear less often than sports, entertainment, and lifestyle stories. In a 30-day period (from 11 July to 9 August 2004 inclusive), a daily sampling of the site found that 73 per cent of the 390 news stories were on sports, entertainment, and lifestyle. Many of these articles were actually longer than the 'serious' news articles. The entertainment and lifestyle articles focused on providing consumer information and advice for good living (e.g health, travel, fashion, finance). And many (47 per cent) of the entertainment and lifestyle articles were 'sponsored stories', with advertisements and links to sponsor sites for readers to find appropriate product solutions to the consumer needs and problems outlined in the stories. These sponsored stories or advertorials are not even labelled as such. The reader of the site is assumed to be a consumer, positioned as a subject who is more interested in news about products and personal needs than wider community issues and problems.

In comparison to these corporate hubs, the commercial (particularly the 'serious') news sites tend to make greater effort in their news coverage to perform the role of the public sphere of rational deliberation. However, news media sites also tend to be moving towards a consumer model. This is particularly noticeable with the increasing encroachment of advertising into editorial space (Boczkowski, 2002, p. 275). Not only is advertising taking up significant room above and alongside news clips, but on many news sites 
marketing links are mixed in with news links, advertisements are placed within editorial columns, and pop-up advertisements distract the reader. Moreover, marketing and advertising personnel are having an increasing influence on what gets reported, via topic selection and budget allocation (Boczkowski, 2004). This has not developed terribly far in New Zealand with the main professional commercial news sites (stuff.co.nz, nzherald.co.nz, tvnz.co.nz), although advertisements do surround and interrupt news stories. Moreover, direct reader contribution and critique of news discourse, so nicely enabled by the internet and often central to independent media sites, is normally not invited (the case for the three main New Zealand sites named above).

Thus, a non-critical, consumer model of communication is being promoted by dominant online hubs and increasingly by media sites. The situation seems to parallel the mass media. However, the internet as a whole differs from corporate broadcasting in that it continues to offer multiple spaces for 'alternative' discourse. The internet offers an extension of the public sphere by extending the means for open and reflexive debate over that offered previously. Even while most publicly-oriented engagement online is spent within corporate spaces that promote individualized and instrumental practices, civic groups are using the medium to organize and deliberate internally as well as deploying it to voice alternative positions and contest dominant discourses online and offline.

\section{Corporate threats to the freedom to communicate online}

However, some critical commentators point out that the very freedom to communicate online (the public domain aspect of the internet) is under threat given the increasing corporate ownership and control of the very form of the internet, encouraged by neo-liberal regulatory environments (Bollier \& Watts, 2002; Dahlberg, 2004; Lessig, 2001, 2004). The threat is not so much the total control of attention, given that communication spaces would in all likelihood be made commercially available for public and private use. The threat is that of corporate discrimination against particular communication (e.g. radical anti-corporate information). With total ownership of the means of communication nothing on the internet would be autonomous from the possibility of corporate control. While this paper has focused on current practices and limitations, this total ownership scenario must be discussed briefly given that it poses a real threat to the future of the online public sphere. 
Analysis of current trends indicates that this threat to the internet's democratic form exists at the 'levels' of content, software, bandwidth, and management (Dahlberg, 2004). ${ }^{12}$ At the content level, evolving intellectual property law (copyright, trademark, patent, and antihacking laws) and digital rights management technologies (supported by law criminalising the breaking of such systems) are driving the commodification of information, and subsequently limiting the free access to online content (Bollier \& Watts, 2002; Lessig, 2001, 2004; May, 2000; Dahlberg, 2004). At the software level, the increasing corporate ownership and control of both the internet's applications and operating software is leading to the transformation of the internet's architecture from an open, free space into a closed, controlled system (ibid). At the bandwidth level, the dismantling of state monopolies and cross-ownership legislation is being accompanied by an increasing domination of network transmission by large communications corporations, which also operate as media content companies, opening up the very real possibility for content discrimination (already undertaken by some cable companies in the United States) (Dahlberg, 2004; McChesney, 2002, 2004). New Zealand is a case in point. With one of the most de-regulated media and telecommunications sectors in the world, internet network transmission has become dominated by just a few carrier-content companies, with Xtramsn carrying 50 per cent of service and Telstra Clear (Paradise), iHug, and ClearNet making up another $30 \%$ (See www.redsheriff.com/nz/content/market.html). Discrimination is made ever more likely with the supply of broadband internet by cable, satellite, and wireless companies that are in most countries, including New Zealand, not covered by common carrier or open network rules, unlike many copper-wire telephone systems (Bollier \& Watts, 2002; Sallet, 2003). ${ }^{13}$ Gatekeeping technologies are presently being wired into broadband networks globally in order to more effectively control 'markets' (Winseck, 2002). Discrimination has already taken place within cable networks in the United States (Dahlberg, 2004). Finally, there are limitations at the level of the internet's management, which is presently in the hands of various international authorities - such as the World Wide Web Consortium (W3C), the Internet Engineering Task Force, and the International Corporation for Assigned Names and Numbers. These authorities are in theory open and democratic, but are increasingly coming under the influence of neo-liberal ideologues and corporate powers that are pushing for the development of the internet as a privately 
controlled space for free trade rather than a public space of free communication (Bollier \& Watts, 2002, p. 28; Salter, 2003). Analysis at all four levels indicates that the Internet is moving towards a closed, commercial, discriminatory system, threatening the autonomy of online communication. Soon it may not only be a challenge to attract online attention, it may actually be difficult to get one's message (particularly if oppositional to dominant ideologies) carried by those who own the lines.

\section{Expanding the online public sphere?}

In this paper I have undertaken an exploratory overview of the increasing corporate domination of attention for publicly-oriented information and interaction, drawing from New Zealand examples and overseas research. More research is needed to detail the extent of this colonization and its specific effects on communicative practices of various kinds, in various contexts. However, we can very generally conclude that corporate hubs and news media sites promoting conservative discourses and consumer practices are capturing much of the attention for what is signified as online public communication. This situation is leading to a marginalisation of online critical communication. Critique of dominant views and articulation of alternative positions is largely being confined to the sidelined discussion spaces of corporate hubs and commercial news media sites, and to the marginalised cyberspaces of alternative media and civil society groups. Moreover, the very freedom to engage in open, reflexive debate online may be under threat from the increasing corporate ownership and control of the internet's form.

Despite this situation, extensive open and reflexive interaction continues to take place online. The internet's fundamental software (the TCP/IP and WWW protocols) remains in the public domain and the medium continues to provide significant spaces of counter-discourse. As noted earlier, the situation is much like print publishing, where many diverse publications circulate widely while struggling for audience attention against the powerful news media. Given the interlinked nature of contemporary mediated cultures, we could assume that opinions and critiques expressed through 'alternative' communicative spaces will ultimately find their way into the public sphere at large and hence affect dominant discourses. This movement towards a more inclusive discursive situation constitutes an extension of democracy. But to what extent is this happening or can this happen? 


\section{THE INDIGENOUS PUBLIC SPHERE}

There are a number of more specific questions that stem from this general question, including: How successful are counter-discursive spaces at gaining voice and facilitating debate in dominant sites online and offline? What are the limiting factors involved in this process, and which specific strategies work? Does this counter-discourse in fact largely remain within marginalised like-minded 'deliberative enclaves' (Sunstein, 2001)? Are there intermediary sites that are able to feed 'alternative' voices into mainstream discourse (e.g., this may be the case with an 'independent' yet 'professional news' site like Scoop.com), or does this feed mostly rely upon interpersonal communication? These questions require focused case study research of online civil society, research that is beginning to be taken seriously by a number of internetdemocracy researchers (see, Bennett, 2003; Gallo, 2004).

Policy questions also need to be asked. First, we need to ask what regulation is necessary to ensure the internet remains in the public domain. Second, we need to ask what cultural policy measures would ensure alternative and critical voices are heard and debate is broadened in terms of both form and content? Work on both these questions is currently being undertaken from a critical political economy perspective (see Dahlberg, 2004, 2005). The New Zealand Government (2004) has recently released a Digital Strategy in which it outlines, within an 'information society' ideological framework, its efforts and plans regarding facilitating citizen internet access and education. It focuses on connecting all citizens to the internet and giving them the skills to use it. This is a start, but it is not enough. The policy fails to address the unequal distribution of social power that leads to the reinforcement of dominant discourses online. What is needed for the internet to more fully fulfil its democratising potential is consideration of ways to safeguard and make visible 'alternative' publicity online. This will require some intervention in the corporate ownership and control of cyberspace, but is unlikely to be undertaken by central government in the current neo-liberal environment. It will be up to progressive communications academics and media activists not only to continue their critical investigation of the possibilities and threats to the internet extending the public sphere, but to push for cultural policies that support open and autonomous spaces of discourse online and offline.

\section{Notes}

${ }^{1}$ The remaining two state radio channels, after the sale of most state radio stations, are still commercial-free and 'public service' (one is purely classical music, the 
other promotes a liberal-middle class world view). For more details on the neo-liberal restructuring of the New Zealand state sector and the privatisation and commercialisation of New Zealand media under successive governments, see Hope (1999). For more details of New Zealand and Pacific media ownership see Rosenberg (2002) and the Pacific Journalism Review edition on media ownership and democracy, September 2004 (10 number 2).

${ }^{2}$ According to ACNielson 78 percent of New Zealanders have access to the internet, with 63 percent 'regular users', defined as using the internet at least once in four weeks (data from December 2003). See www.acnielsen.co.nz/ MRI_pages.asp?MRIID=11 (last accessed August 6 2004).

${ }^{3}$ The Piper Portal offers a directory of many New Zealand web sites, but does not list email, web discussion groups, and more radical sites such as independent media initiatives.

${ }^{4}$ The most widely discussed aspect of the 'digital divide' concerns the lack of equipment and skills to enable individuals to access the internet. This lack is a serious limitation to the internet extending the public sphere. However, 'digital divide' rhetoric may also be used to mask attempts to get more people into spaces of virtual consumption. This paper takes a more expansive definition of the 'digital divide' and asks about the equality of discourse online: even if everyone was to be given full access and the necessary skills, would there be an expansion of the public sphere of open and reflexive debate between a plurality of contesting positions, or simply the performance of public communication dominated by certain voices?

${ }^{5}$ Internet research has consistently found that fewer than half of those who sign up for an ISP change the default homepage (Hargittai, 2000, p. 130).

${ }^{6}$ Telecom New Zealand's Xtra.co.nz gained 50 per cent of the national ISP market share (customers) by aggressive marketing and pricing, pricing afforded by Telecom's ownership of the copper wire telephone network in the country (see www.redsheriff.com/nz/content/market.html). Telecom was the state-owned monopoly telephone network until the neo-liberal restructuring of the New Zealand economy and state sector, during which time Telecom was privatised (1990) and the telecommunications industry was opened up to foreign ownership and competition (Hoar \& Hope, 2002). Xtra.co.nz allied with MSN in 2001 to become Xtramsn.co.nz.

${ }^{7}$ See regularly updated internet traffic pattern statistics for selected countries at www.nielsen-netratings.com/news.jsp?section=dat_to and www.clickz.com/stats/ (last accessed July 25, 2004). Google may be considered more a 'pure' portal than a hub since it does not clutter its site with proprietory and cross-promotional material. This is one reason often cited for Google's popularity. However, through sponsored links that appear beside search results, Google does act to bias certain online information and experiences.

${ }^{8}$ The New Zealand state broadcaster TVNZ is required to follow minimum pub- 


\section{THE INDIGENOUS PUBLIC SPHERE}

lic service obligations. However, it is a commercial and conservatively focused media organization and its website Nzoom.com follows suit. The New Zealand Herald is the flagship newspaper of the Wilson and Horton media company. Stuff is the web home of Independent Newspaper Ltd.

${ }^{9}$ Based on the author's observations of the 'politics' discussions on Guardian and New York Times during June-July 2004. Flaming can be found throughout cyberspace. However, it is not essential to online communication. Rather, flaming can be encouraged or discouraged by the type of environment that is structured by the design of sites, rules of engagement, and the management of forums. Flame-free spaces of public debate are facilitated online by democratic projects such as Minnesota EDemocracy (see Dahlberg, 2001).

${ }^{10}$ More than a decade ago, cyber-libertarian guru Nicholas Negroponte (1995) predicted a future in which internet information agents would gather personalized news for each person, news focused specifically on their interests from every news source on the planet. This would provide for a 'daily me' news published or webcast in 'an edition of one'. This 'daily me' has yet to be widely provided or used. However, various news media corporations do currently provide a service that enables users to select the type of news they wish to see, and this is then served via email or a personalised webpage (e.g. My Yahoo!, My MSN).

${ }^{11}$ This research was undertaken up until 9 August 2004. After this date the Xtramsn site was re-designed. Initial inspection of the new site indicates that it has moved even more towards an entertainment format, in preparation for increased broadband services.

${ }^{12}$ See Dahlberg (2004) for an exploration of the implications for the online public sphere, in the context of corporate colonization, of evolving intellectual property laws, digital rights management technologies, operating software, gate-keeping technologies, and internet management systems.

${ }^{13}$ Common carrier status means that network suppliers are prohibited from interfering with online communication and from limiting what devices and applications can be carried on the network.

\section{References}

Barney, D. (2000). Prometheus wired: The hope for democracy in the age of network technology. Sydney: UNSW Press.

Barney, D. (2003). Invasions of publicity: Digital networks and the privatization of the public sphere. In Law Commission of Canada (Ed.), New Perspectives on the Public/Private Divide (pp. 8-122). Vancouver: University of British Columbia Press.

Bauman, Z. (2002). Society under siege. Cambridge: Polity.

Benhabib, S. (1996). Toward a deliberative model of democratic legitimacy. In S. Benhabib (Ed.), Democracy and difference: Contesting the boundaries of the political (pp. 67-94). Princeton: Princeton University Press. 
Bennett, L. W. (2003). Communicating global activism. Information, Communication \& Society, 6(2), 143-168.

Blumler, J. G., \& Gurevitch, M. (2001). The new media and our political communication discontents: Democratizing cyberspace. Information, Communication \& Society, 4(1), 1-13.

Boczkowski, P. J. (2002). The development and use of online newspapers: What research tells us and what we might want to know. In L. A. Lievrouw \& S. Livingstone (Eds.), Handbook of new media: Social shaping and consequences of ICTs (pp. 270-286). London: Sage.

Boggs, C. (2000). The end of politics: Corporate power and the decline of the public sphere. New York: Guilford Press.

Bohman, J. (1996). Public deliberation: Pluralism, complexity, and democracy. Cambridge, Mass: MIT.

Bollier, D. \& Watts, T. (2002). Saving the information commons: A public interest agenda in digital media. New America Foundation. Retrieved February 8, 2005: http://www.newamerica.net/Download_Docs/pdfs/Pub_File_866_1.pdf

Curran, J., \& Gurevitch, M. (Eds.). (2000). Mass Media and Society (third ed.). London: Arnold.

Dahlberg, L. (2001). The internet and democratic discourse: Exploring the prospects of online deliberative forums extending the public sphere. Information, Communication \& Society, 4(4), 615-633.

Dahlberg, L. (2002). Democratic visions, commercial realities? The corporate domination of cyberspace and the prospects for online deliberation. AntePodium, April. Retrieved February 8, 2005: http://www.vuw.ac.nz/atp/articles/Dahlberg_0204.html

Dahlberg, L. (2004). Cyber-publics and the corporate control of online communication. Javnost-The Public, 11(3), 77-92.

Dahlberg, L. (2005). The corporate colonization of online attention and the marginalization of critical communication? Journal of Communication Inquiry, 29 (2), 1-21.

Dahlgren, P. (2001). The public sphere and the net: Structure, space, and communication. In L. W. Bennett \& R. M. Entman (Eds.), Mediated politics: Communication in the future of democracy (pp. 33-55). Cambridge: Cambridge University Press.

Davenport, T. H., \& Beck, J. C. (2001). The attention economy: Understanding the new currency of business. Cambridge, Mass: Harvard Business School Press.

Dryzek, J. S. (2000). Deliberative democracy and beyond. Oxford: Oxford University Press.

Fortier, F. (2001). Virtuality check. London: Verso.

Gallo, J. (2004). Online oppositional communities as discursive counterpublics. Paper presented at the Association of Internet Researchers Conference. October, Toronto.

Gandy, O. (2002). The real digital divide: Citizens versus consumers. In L. A. Lievrouw \& S. Livingstone (Eds.), Handbook of new media: Social shaping and consequences of ICTs (pp. 448-460). London: Sage. 
Gimmler, A. (2001). Deliberative democracy, the public sphere and the internet. Philosophy \& Social Criticism, 27(4), 21-39.

Goldhaber, M. H. (1997). The attention economy: The natural economy and the net. First Monday, 2(4). Retrieved September 20, 2004: http://www.firstmonday.dk/ issues/ issue2 4/goldhaber/\#dep15

Gomez, J. (2004). Dumbing down democracy: Trends in internet regulation, surveillance and control in Asia. Pacific Journalism Review, 10(2), 130-150

Habermas, J. (1989). The structural transformation of the public sphere: An inquiry into a category of bourgeois society. (Thomas Burger with the assistance of Frederick Lawrence, Trans.). Cambridge, Mass: MIT Press.

Habermas, J. (1996). Between facts and norms: Contributions to a discourse theory of law and democracy (Rehg, William, Trans.). Cambridge: Polity Press.

Hargittai, E. (2000, May 20-23). Standing before the portals: Non-profit content online in the age of commercial gatekeepers. Paper presented at the DIAC 2000 Shaping the Network Society: The Future of the Public Sphere in Cyberspace, Seattle, Washington.

Hargittai, E. (2004). The changing online landscape: From free-for-all to commercial gatekeeping. In P. Day \& D. Schuler (Eds.), Community Practice in the network society: Local actions/global interaction (pp. 66-76). New York: Routledge.

Hoar, P., \& Hope, W. (2002). The internet, the public sphere and the 'digital divide' in New Zealand. The Journal of International Communication, 8(2), 64-88.

Hope, W. (1999). Ideology, communication, and capitalist crisis: The New Zealand experience. In A. Calabrese \& J. Burgelman (Eds.), Communication, citizenship and social policy: Rethinking the limits of the welfare state (pp. 91-110). Lanham: Rowman \& Littlefield.

Kellner, D. (2004). The media and the crises of democracy in the age of Bush-2. Communication and Critical/Cultural Studies, 1(1), 29-58.

Kelsey, J. (2004, February 3). Speech to the ARENA Forum on the Seabed and Foreshore. Retrieved September 24, 2004: http://www.arena.org.nz/sbwetp.htm

Kohut, A., \& Raine, L. (2003). Political sites gain, but major news sites still dominant. Pew Interent \& American Life Project. Retrieved August 20, 2004: http:// www.pewinternet.org

Lessig, L. (2001). The future of ideas: The fate of the commons in a connected world. New York: Random House.

Lessig, L. (2004). Free culture: How big media uses technology and the law to lock down culture and control creativity. New York: Penguin.

Liang, G. (2003). Surveying internet usage and impact in twelve Chinese cities. Beijing: Research Center for Social Development, Chinese Academy of Social Sciences. Retrieved August 20, 2004: http://www.markle.org/index.stm

Light, A., \& Rogers, Y. (1999). Conversation as publishing: The role of news forums on the web. Journal of Computer Mediated Communication, 4(4). Retrieved March 10 2004: http://www.ascusc.org/jcmc/vol4/issue4/light.html

May, C. (2000). A global political economy of intellectual property rights: The new enclosures? London: Routledge. 
McChesney, R. W. (1999). Rich media, poor democracy: Communication politics in dubious times. Urbana: University of Illinois Press.

McChesney, R. W., \& Nichols, J. (2002). Our media, not theirs: The democratic struggle against corporate media. New York: Seven Stories Press.

Ministry of Economic Development (2003, June) Statistics on information technology in New Zealand: Updated to 2003. Information Technology Policy Group. Retrieved August 8, 2004: http://www.med.govt.nz/pbt/infotech/it-stats/it-stats2003/index.html

Murdock, G., \& Golding, P. (2004). Dismantling the digital divide: Rethinking the dynamics of participation and exclusion. In A. Calabrese \& C. Sparks (Eds.), Towards a political economy of culture: Capitalism and communication in the twentyfiirst century (pp. 244-260). Lanham: Rowman \& Littlefield.

Napoli, P. M. (1998). The internet and the forces of 'massification'. Electronic Journal of Communication, 8(2). Retrieved August 20, 2004: http://www.cios.org/www/ ejc/v8n298.htm

Negroponte, N. (1995). Being digital. New York: Alfred A. Knopf.

New Zealand Government (2004, June). Digital strategy: A draft New Zealand digital strategy for consultation. Retrieved August 5, 2004: http://www.med.govt.nz/pbt/ infotech/digital-strategy/

Nielsen//NetRatings (2004, July). Market Intelligence. Retrieved August 6, 2004, available online with subscription only: https://secure.redsheriff.com/mi/cgi-bin/ reports.pl

Papacharissi, Z. (2002). The virtual sphere: The internet as a public sphere. New Media \& Society, 4(1), 9-27.

Papacharissi, Z. (2004). Democracy online: civility, politeness, and the democratic potential of online political discussion groups. New Media \& Society, 6(2), 259283.

Patelis, K. (2000). E-mediation by America Online. In R. Rogers (Ed.), Preferred placement: Knowledge politics on the web (pp. 49-63). Masstricht: Jan van Eyck Akadamie.

Pew Center. (2004). Cable and Internet loom large in fragmented political news universe: Pew Internet and American Life Project. Retrieved August 10, 200: http:// www.pewinternet.org

Rainie, L., Fox, S., \& Fallows, D. (2003). The internet and the Iraq war. Pew Internet \& American Life Project. Retrieved August 10, 2004: http://www.pewinternet.org

Reporters Without Borders (2004) The internet under surveillance 2004. Retrieved August 20, 2004: http://www.internet.rsf.org

Rosenberg, B. (2002). News media ownership: How New Zealand is foreign dominated. Pacific Journalism Review, 8 (1), 59-95.

Sallet, J. (2003). Just how open must an open network be for an open network to be labeled 'open'? First Monday, 8(3). Retrieved February 8, 2005: http:// firstmonday.org/issues/issue8_3/sallet/

Salter, L. (2003). The internet: Potentiality and limits. Paper presented at the Internet Structure and Use Workshop (September 3). London Metropolitan University. 
THE INDIGENOUS PUBLIC SPHERE

Savigny, H. (2002). Public opinion, political communication and the internet. Politics, 22(1), 1-8.

Schiller, D. (1999). Networking the global market system. Cambridge, Mass: MIT Press.

Schultz, T. (2000). Mass media and the concept of interactivity: an exploratory study of online forums and reader email. Media, Culture \& Society, 22(2), 205-221.

Sunstein, C. (2001). Republic.com. Princeton, NJ: Princeton University Press.

Tanner, E. (2001). Chilean conversations: Internet forum participants debate Augusto Pinochet's detention. Journal of Communication, 51(2), 383-403.

Wilhelm, A. G. (2000). Democracy in the digital age: Challenges to political life in cyberspace. London: Routledge.

Winseck, D. (2002). Netscapes of power: convergence, consolidation and power in the Canadian mediascape. Media, Culture \& Society, 24(6), 795-819.

Young, I. M. (2000). Inclusion and democracy. Oxford: Oxford University Press.

Zimmerman, A., \& Koopman, R. (2003). Political communication on the internet. Part 1: Representative sample of websites: Europub.com Retrieved January 20, 2005: http://europub.wz-berlin.de/project\%20reports.en.htm

Dr Lincoln Dahlberg is currently an independent researcher living in Wellington, New Zealand, and co-editor of the journal New Zealand Sociology. His research involves a critical investigation of the practices and meanings surrounding internet use, with particular focus on the extension of democratic cultures. This research was supported by funding from the New Zealand Foundation for Research, Science, and Technology. The author also wants to thank Brennon Wood for his support, advice, and friendship, and to Alastair Thompson, the general editor of Scoop.co.nz, for helping source information on New Zealand Internet usage patterns.

L.J.Dahlberg@xtra.co.nz 